\title{
TRANSFORMAÇÕES ECONÔMICAS, POLÍTICAS E SOCIAIS NA AMÉRICA DO SUL E A EDUCAÇÃO COMO ESPAÇO DE DEFINIÇÃO HEGEMÔNICA
}

\author{
PROF. DR. ENÉAS ARRAIS NETO ${ }^{1}$ \\ ORCID: https://orcid.org/0000-0002-5919-4554 \\ PROFA. DRa. TÂNIA SERRA AZUL MACHADO BEZERRA ${ }^{2}$ \\ ORCID: https://orcid.org/0000-0002-3982-4758 \\ PROF. DR. MARCELO VIEIRA PUSTILNIK ${ }^{3}$ \\ ORCID: https://orcid.org/0000-0002-1139-5154
}

\begin{abstract}
RESUMO: Artigo de teor ensaístico, elabora a leitura das transformações sociais, políticas e econômicas acontecidas no Brasil, no quadro das mudanças gerais progressistas ocorridas na América do Sul no decurso dos anos 2000-2014. Avalia o papel e os encaminhamentos políticos tecidos pelos governos progressistas desse período e constitui a primeira análise dos processos políticos, sociais e culturais reacionários, investigando alguns de seus mecanismos institucionais na disputa de hegemonia e imposição do reacionarismo conservador. Discute o novo papel das forças emergentes dos BRICS e a realidade de retrocesso mostrado no Brasil no âmbito da nova organização mundial que a todos ameaça, tanto do ponto de vista da paz, quanto ambiental. A modo de remate, situa a educação escolar, do ensino básico ao superior, como seara da disputa fundamental - e atualmente central - para a resistência dos setores populares e progressistas, a fim de conformar um encaminhamento humanizante e crítico para a sociedade. São reflexões importantes para a resistência e a sobrevivência ante o retrocesso que está em andamento.
\end{abstract}

Palavras-Chaves: Capitalismo global, economias regionais, América Latina, luta social, educação.

\section{ECONOMIC, POLITICAL AND SOCIAL TRANSFORMATIONS IN SOUTH AMERICA AND EDUCATION AS A SPACE OF HEGEMONIC DEFINITION}

\begin{abstract}
This essay is an interpretation of the social, political and economic transformations that took place in Brazil, within the framework of the general progressive changes that took place in South America during the years 2000-2014. It evaluates the role and the political directions woven by the progressive governments of this period and constitutes the first analysis of the reactionary political, social and cultural processes, investigating some of their institutional mechanisms in the dispute for hegemony and imposition of conservative reactionaryism. It discusses the new role of the emerging forces of the BRICS and the reality of retrogression shown in Brazil within the new world organization that threatens us all, both from the point of view of peace and the environment. As a conclusion, it situates school education, from basic to higher education, as a field of fundamental dispute - and currently central - to the resistance of the popular and progressive sectors, in order to conform a humanizing and critical
\end{abstract}

\footnotetext{
${ }^{1}$ Universidade Federal do Ceará (UFC). Fortaleza, CE, Brasil. <eneas-arrais@hotmail.com>

${ }^{2}$ Universidade Estadual do Ceará (UFC). Fortaleza, CE, Brasil. <taniasamb@hotmail.com>

${ }^{3}$ Universidade Federal de Santa Maria (UFSM). Santa Maria, RS, Brasil. <marcelo.pustilnik@ufsm.br> Educação em Revista|Belo Horizonte|v.37|e233354|2021
} 
direction for society. These are important reflections for resistance and survival in the face of the ongoing backlash.

Keywords: Global capitalism, regional economies, Latin America, social struggle, education.

\title{
TRANSFORMACIONES ECONÓMICAS, POLÍTICAS Y SOCIALES EN SUDAMÉRICA Y LA EDUCACIÓN COMO ESPACIO DE DEFINICIÓN HEGEMÓNICA
}

\begin{abstract}
RESUMEN: Este artículo basado en ensayos elabora la lectura de las transformaciones sociales, políticas y económicas que tuvieron lugar en Brasil, en el marco de las transformaciones generales progresivas que ocurrieron en América del Sur durante los años 2000-2014. Evalúa el papel y las orientaciones políticas tejidas por los gobiernos progresistas de este período, y construye un primer análisis de los procesos políticos, sociales y culturales reaccionarios, investigando algunos de sus mecanismos institucionales de disputa sobre la hegemonía y la imposición del reaccionario conservador. Discute el nuevo rol de las fuerzas emergentes de los BRICS y el escenario de retroceso presentado en Brasil dentro de esta nueva organización mundial emergente que nos amenaza, tanto desde el punto de vista de la paz como del ambiente. Termina situando la educación escolar, desde la educación primaria hasta la educación superior, como un campo de disputa fundamental y actualmente central para la resistencia de los sectores populares y progresistas, y para la construcción de una referencia humanizadora y crítica a la sociedad. Reflexiones importantes para la resistencia y la supervivencia frente al revés que está en marcha.
\end{abstract}

Palabras clave: Capitalismo global, economías regionales, América Latina, lucha social, educación.

\section{ECONOMIAS REGIONAIS VERSUS CAPITALISMO GLOBAL}

O grupo de estudos e discussão francês, intitulado Nouvelle Marx Confrontation desenvolveu, no decurso dos anos de 2000 a 2010, a análise do novo ciclo de desenvolvimento mundial capitaneado pelo BRICS (Brasil, Rússia, Índia, China e África do Sul - não necessariamente nesta ordem), articulado às modalidades da gestão do capital promovidas pelos sistemas financeiros e acionários do capitalismo mundial (CHESNAIS et all, 2003). A reversão das políticas econômica e estatal que emergiu desde a virada do milênio, exigida pela debacle política do neoliberalismo yuppie e pela exaustão social gerada pela miséria decorrente de suas políticas à extensão dos anos de 1990 em todo o mundo, não levou necessariamente a tentativas de mudança mais profundas na economia e nos modelos sociais.

Vimos emergir, na primeira década do novo século, outra ordem mundial, econômica e política, e com uma diversificação (relativa) de configurações sociais e referências culturais, que passaram a apontar, se não para novos caminhos, para "novas formas de caminhar". Efetivamente, é necessário reconhecer que não há, e nem mesmo se propõe, a ruptura com a ordem capitalista, com a lógica fundamental do capital, mas é também forçoso reconhecer a instauração de caminhos novos para o capitalismo, mormente em setores periféricos aos antigos centros da tríade (EUA-EURO-Japão). Esses "caminhos novos" refletem aspectos diferenciados das relações de poder internacionais, influenciados por transformações de ordem política e econômica, incluindo o fato de que os próprios centros do capitalismo mundializado passaram a sofrer com as crises, anteriormente restritas às economias dependentes. São crises que despontam com epicentro nos EUA, e na Europa refletem um processo de transformação qualitativa da estrutura mundializada do capital, levando ao reordenamento das polaridades econômicas com a emergência de uma pluralidade de centros dinâmicos "médios" na produção mundial, conquanto articulados ainda pelas dinâmicas dos fluxos financeiros, influências de

\footnotetext{
${ }^{4}$ Denominamos "neoliberalismo yuppie" a cultura festiva do neoliberalismo abraçada por setores tecnocráticos da economia e repercutida pela classe média que se projetava com acesso ampliado ao consumo supérfluo diferencial. Educação em Revista|Belo Horizonte|v.37|e233354|2021
} 
mecanismos cambiais etc. Como exemplo desse novo quadro, a reorganização política da América Latina, desde os governos Lula, no Brasil (que capitaneou esse processo nas esferas da América do Sul e na articulação com África, China, Coréia e Rússia), ao lado de Hugo Chavez (Venezuela), Evo Morales (Bolívia), José Mujica (Uruguai), com o apoio dos Kirchners (Argentina), permitiu a ruptura com o projeto da ALCA (de interesse dos EUA e de seus representantes nas elites nacionais desses países), reforçando o MERCOSUL. Essa reorganização da produção econômica, da articulação política e dos mercados regionais do subcontinente sul-americano, ao lado da criação de outros formatos formas de agrupamento (BRICS, G20, entre outros) e, mesmo, o novo estádio das economias chinesa, indiana, brasileira e russa, levou ao redimensionamento das possibilidades de inserção dessas economias nacionais e regionais no quadro mundial capitalista.

Em cada uma destas regiões geoeconômicas ou geopolítica e econômicas, a divisão do trabalho direciona as atividades que produzem maior valor agregado para os países e regiões centrais, os polos ainda mais poderosos e também reais do sistema, transferindo as atividades intensivas no uso de mão de obra e energia, ou os setores de alto teor poluente para as áreas agregadas ou politicamente subordinadas. Nesta divisão de trabalho não apenas internacional, mas já globalizada e regionalizada, o papel desempenhado pela educação no posicionamento relativo de cada país se tornou mais importante. Cabe evidenciar aqui o fato de que Educação é pensada, nesse formato, como atividade reduzida à escolarização, tomando assim um processo social amplo e complexo, que envolve experiências existenciais diversas em variados grupos relacionais e modalidades culturais múltiplas, em apenas uma de suas expressões sociais - a escola. Esse reducionismo já se mostra como princípio deletério para definições políticas globais e educacionais, especificamente. Quando entendida economicamente, com amparo na mesma lógica do senso comum, principalmente como nível de escolarização, uma gama de aspectos educacionais fundantes do desenvolvimento da personalidade de cada trabalhador, de cada cidadão, de cada pessoa, afinal, torna-se elemento de restrição e não de ampliação de suas capacidades e potenciais. Esse ponto, em si, já leva a muitos questionamentos referentes à propositura desse tipo de enfoque que despreza a centralidade do humano, repondo uma centralidade reificada sob a razão do capital.

O aspecto central posto em dúvida, mesmo nesse enfoque, é até que ponto o patamar de escolarização se tornou realmente um fator decisivo ou, ao menos, um determinante deveras relevante daqueles processos do desenvolvimento econômico e liderança tecnológica, no sentido que normalmente se atribui a ela - escolarização? O conjunto trabalho barato, inovações tecnológicas e produtivas e acesso a mercados parece ser ainda o núcleo da fórmula defendida pelas concepções liberais. Supondo que a alta tecnologia se desenvolveria dentro das economias mais importantes, o que seria, ao lado das novas condições de desenvolvimento subjetivo e cognitivo o grande papel da parcela dos técnicos de alta qualificação dentro do sistema produtivo, a elevação em níveis intermediários (ensino-escolarização fundamental e média, e mesmo escolarização superior de baixo nível científico), apenas eleva o patamar de execução e absorção de tecnologia importada.

Chesnais (2003) torna claro o papel da educação-escolarização, tanto como parte da estrutura de condições para o desenvolvimento da produção como um todo, ou como "lugar" de exploração de mão de obra barata e altamente qualificada, utilizada para subcontratação (terceirização) de serviços, como é o caso da transferência de serviços acessórios da área bancária e financeira em geral, e de processamento de dados, para regiões da Índia e da Escócia, desde o início dos anos de 1990, em busca de trabalho qualificado e barato. Esse caso exemplar e a constatação dele decorrente sugerem as determinações do movimento em que o padrão educacional não necessariamente determina $\mathrm{o}$ desenvolvimento ou instalação de setores econômicos de alto valor agregado num país ou região. Isto posto, impende reconhecer a ideia de que a escolarização não deixa de ser elemento importante (mesmo entre outros) do direcionamento na distribuição dos empregos de melhor remuneração dentro dos processos produtivos.

Há, entretanto, críticas mais diretas à potencialidade do processo educativo, exprimindo a noção de que melhor treinamento e mais alto nível educacional não asseguram emprego, não possuem o condão de criar postos de trabalho, apenas aumentam as chances de inclusão cíclica como mão de obra preferencial para exploração do capital, num processo em que outros (outros indivíduos, outras regiões, outros países) serão excluídos ou preteridos (CHESNAIS, 1996). Havendo se tornado historicamente 
um veículo de ascensão individual, ou de distinção de classe, a educação assumiria seu papel 'perfeito' como uma "escada" de subida social somente dentro de esquemas duais, onde há "boa educação" para alguns, e pior, pouca ou nenhuma educação escolar para outros. A alegoria perfeita para esse processo é a da gangorra ou da balança de pratos: quanto maior o desequilíbrio, a ascensão de um lado depende do descenso do lado oposto - competidor. Por fim, a indagação definitiva é: -o que aconteceria se atingíssemos um nível elevado e universal de qualificação profissional? Neste caso, é claro, a educação e a qualificação não poderiam determinar os "melhores empregos" para todos, mesmo considerando o argumento como verdadeiro.

Este quadro extremo de alta qualificação generalizada somente determinaria o melhor dos mundos para o capital, que poderia escolher os mais baratos entre os bem qualificados trabalhadores, que estariam competindo ferrenhamente para ocupar os mesmos postos de trabalho necessários à permanência da estrutura produtiva capitalista. É necessário redirecionar o sentido da educação formal representada pelo sistema escolar, no senso mais profundo que Marx preconizava para o termo 'superação', a emergência de algo novo que 'retorce' o sentido de algo, negando-o, mas, ao mesmo tempo, incorporando-o parcialmente e indo além.

A ideia que postulamos aqui não é a desqualificação da educação-escolarização ou a negação de sua importância social. Primeiramente, defendemos o ponto de vista de que o real papel desempenhado pelo sistema educativo-escolar e pela educação, como fenômeno em geral, no capitalismo globalizado e em cada bloco histórico nacional com ele articulado, deve ser compreendido propriamente, se queremos intervir no sentido de atuarmos conscientemente sobre essas realidades.

\section{O NOVO QUADRO POLÍTICO E ECONÔMICO CONTINENTAL E A POSSIBILIDADE DE POLÍTICAS SOCIAIS PROGRESSISTAS}

Nos últimos anos, a emergência das economias chinesa, indiana, brasileira e russa assumiu um papel importante no reposicionamento relativo dos grupamentos regionais, abrindo importantes perspectivas e novas possibilidades históricas para o desenvolvimento econômico e social dos países periféricos aos grandes centros históricos do capital mundial, e alternativos aos processos hegemônicos políticos, econômicos e sociais.

No processo, ainda em curso, da crise financeira iniciada no maior centro econômico global, e cujos rumos se encontram abertos, a disputa pela hegemonia mundial articula capital financeiro, estruturas produtivas e organização social e política, em âmbitos, escalas e níveis diversos - nacional, regional e inter-regional. Não se deve esquecer o papel, no aporte de recursos de P/D (pesquisa e desenvolvimento de processos e produtos) e de desenvolvimento tecnológico de ponta, desempenhado pelo setor industrial militar dos EUA e OTAN (Alemanha, França, Inglaterra, Itália, Suécia, Bélgica, Holanda et alii). (ARRAIS NETO, 2008).

A posição ainda dominante dos Estados Unidos nas agências internacionais de organização econômica (FMI, Banco Mundial, OMC, GATT etc.), juntamente com sua condição de potência hegemônica política e militar do sistema, ainda consegue influenciar poderosamente a economia mundial. Teve sucesso em mudar as regras do comércio internacional em muitos aspectos, redirecionar produção, determinar novas modalidades e conteúdos do consumo e, principalmente, direcionar os fluxos financeiros internacionais em seu benefício, estabelecendo o capital financeiro e o desenvolvimento tecnológico como eixos do capitalismo mundial. As guerras localizadas (Guerra do Golfo, Afeganistão, Iraque) e conflitos regionais são grandes mercados para a indústria armamentista e laboratório de desenvolvimento de novas tecnologias militares às custas de centenas de milhares de vidas, consideradas irrelevantes na contabilidade mórbida desses setores empresariais e seus lobbies nos congressos e governos centrais, mormente o dos Estados Unidos da América.

Esta hegemonia "americana", que articula intervenções militares de cunho econômico, retaliações políticas e mecanismos variados de intervenção internacional, passou a ser alvo da perspectiva de sombreamento pelo desenvolvimento das economias chinesa, russa, sul-americana e indiana, principalmente, e pela magnitude da crise interna do sistema produtivo estadunidense, sem que se possa, ainda neste momento, aquilatar o influxo desse processo sobre as modos de reprodução e hegemonia do capital financeiro global. Observe-se que o distanciamento do aparelho militar estadunidense em relação ao restante do mundo, tanto em termos quantitativos quanto qualitativos, o erigia, no curto prazo, em 
superpotência militar "única" e gendarme mundial (BERTONHA, 2013). A reunião do BRICS trouxe uma nova perspectiva neste cenário; desenvolveremos uma breve consideração sobre isso mais adiante. A ameaça constante que paira sobre qualquer país ou região insubmissa é considerável, e as incursões 'aventureiras' dos marines, da força aérea e do exército ianque relembram permanentemente ao mundo os riscos da opção por caminhos de confrontação aos ditames do centro da economia capitalista atual. Voltando ao tema do ponto de deflexão no poderio militar estadunidense, há que se considerar os últimos sérios confrontos que se deram na Síria em 2018. Em 13 de abril daquele ano, a OTAN decidiu bombardear a Síria, alegando ajuda humanitária para a região - como se fosse possível ajuda humanitária bombardeando um país - diferentemente dos bombardeios a Bagdad, ao qual assistimos como espetáculo midiático, não se soube de nenhuma imagem, nenhuma notícia sobre tal bombardeio nos noticiários, nem no dia seguinte, mesmo hoje na internet quase nada se encontra. Tentando entender e encontrar uma resposta, somente uma informação nos pareceu relevante.

Segundo os russos, 71 dos 103 mísseis foram derrubados pelo sistema de defesa de Assad, que nos últimos 18 meses foi completamente refeito por Moscou. As primeiras indicações são de que não houve vítimas do ataque e que a unidade militar que o bombardeio mirou sofreu apenas pequenos danos. Vídeos que emergiram após o ataque ocidental mostram o sistema de defesa sírio em plena operação. (DWb, 2018, p.1)

Do ponto de vista militar, o ataque foi um fracasso, os grandes jornais não noticiaram isso! Outro fato que ocorreu naquele cenário foi a resposta russa no desenvolvimento de misseis, apresentando um hipersônico em março de 2018, considerado uma arma imbatível até o momento (BBC, 2018). Aliando-se ao desenvolvimento russo, os chineses e indianos trabalham em conjunto, já representando uma força militar capaz de barrar as ameaças estadunidenses neste panorama de quase guerra.

Nos últimos anos (2012-2019), emerge outra modalidade de intervenção 'subterrânea', baseada em formas anteriores, mas agravada pela utilização de novos instrumentos de mobilização social: a guerra híbrida (ESCOBAR, 2017). A intervenção política mobilizando setores sociais pequenoburgueses, no sentido da destituição de governos democratizantes de centro-esquerda na América Latina e, mais recentemente, na Europa, vem se tornando o aspecto desequilibrador da continuidade de políticas econômicas e sociais progressistas, bem como da consequente ascensão de opções ao poderio estadunidense (ARRAIS NETO, 2014). Os processos de destituição dos governos latino-americanos na Argentina, no Brasil, no Peru, no Equador, e as tentativas em vários outros países dessa macrorregião geopolítica, apontam para novos meios de manipulação ideológica, em adição ao emprego massivo da internet e suas expressões de mídia e redes virtuais. O 'cultivo' de novas formas da direita, hoje religiosa e furibunda, aponta para processos educativos, centrados não mais na escolarização (que esses grupos ideologizados da direita tentam voltar a controlar estritamente), mas na utilização de 'igrejas', do 'cristianismo fundamentalista', do 'pentecostalismo cristão', associado a discursos explícitos de violência xenofóbica contra imigrantes, xenofobia regional (contra nordestinos, no Brasil), misoginia, machismo, racismo, sexismo e, não menos importante ou central - classe trabalhadora organizada (sindicatos, centrais sindicais, MST, MTST, Via Campesina).

Retornemos, porém, ao problema da relação direta escola-produção, após essa digressão historicizante. É fundamental que se compreenda o caráter do capitalismo centrado e dirigido pelas finanças, que já assumiram formato virtual. Primeiramente, no panorama de manutenção da hegemonia do capital financeiro em condições semelhantes às de sua forma de atuação atual, a separação produçãoapropriação de mais-valia e a emergência do capital monetário como um setor parasítico do capital, já havia sido claramente exposta por Marx (O Capital, livro III, capítulo XXV, 1984). Ao lado de todas as implicações sociais deste processo, que inclui dívidas públicas exorbitantes, fortunas digitais, economia fiduciária, soberania transnacional dos mercados de ações e de câmbio, entre outras, aconteceu uma mudança estratégica na posição relativa da indústria e das finanças, com importantes consequências para a divisão do trabalho.

O deslocamento do setor industrial para uma posição subordinada, dentro da estrutura do capitalismo mundializado, determinou também sua subalternidade global, na contextura do modelo social engendrado com suporte relações do capital. Todo este movimento, com seus deslocamentos de eixo gravitacional da produção e maior volatilidade financeira, levou, no primeiro momento, ao 
enfraquecimento das definições políticas, inclusive das políticas públicas de Estado. Isto foi um movimento muito claro, explicável, na medida em que o Estado é também um partícipe e constituinte das relações capitalistas gerais da sociedade, tendo perdido ou reduzido gravemente, nos anos de 1980 e 1990, a possibilidade de orientar estratégias econômicas de médio e longo prazos, definindo sua atuação, contrariamente, com esteio na necessidade de retorno e lucratividade, em curto prazo e com liquidez permanente, do capital monetário (ARRAIS NETO, 2008).

No refluxo desse momento de hegemonia absoluta e inquestionável do capital financeiro (característico dos anos 1980 e 1990), o início do século XXI apontou para uma conjuntura um pouco mais crítica dos mercados financeiros (mesmo que crítica ainda incipiente e mantida a submissão objetiva aos mercados financeiros globais). Aponte-se, ainda, o retorno da produção agrícola e industrial como elemento de central importância na disputa intersetorial do capital (ARRAIS NETO, 2008). Por um lado, a crise internacional desencadeada com base nos mercados financeiros e de câmbio, ocorrida em 199798, desnudou a fragilidade das políticas econômicas nacionais e mesmo de suas estruturas produtivas, diante dos fluxos monetários que demandam aplicações de alta rentabilidade e liquidez absoluta (ARRAIS NETO 2008). A crise ianque mais recente dos mercados financeiros e de ações, deflagrada com o estouro da chamada "bolha" do mercado imobiliário dos EUA (2008), que contagiou o mundo com a especulação creditícia do sistema bancário americano, é um sintoma da possibilidade de a maior economia capitalista do mundo entrar em um ciclo recessivo e afundar parte do mundo (os demais países sob influência de sua economia) sob o peso da inflação dolarizada, dos redirecionamentos de fundos de capital, ou de processos de estagnação decorrentes dos modos de "salvamento" financeiro de suas economias nacionais adotadas pelos Estados centrais (ARRAIS NETO, 2008).

A retração dos programas sociais estatais, das políticas públicas em geral, bem como o agravamento da desigualdade de classe nessas regiões centrais do capitalismo, são sintomáticos do preço que recai prioritariamente sobre a classe trabalhadora desses países, com o gravame incidente sobre as nações e regiões de menor poder político e econômico em suas áreas de influência (BRAZ, 2017). A dependência da economia brasileira diante do aporte constante de capital externo, vinculada ao encaminhamento submisso das políticas sociais e econômicas aos ditames liberais, tolheu a condição de instauração nacional (pelo menos no caso brasileiro, à extensão dos anos de 1980-90) de políticas de longo prazo que revertessem o quadro de dependência externa e de agravamento das condições sociais internas. O redirecionamento político e econômico regional da América Latina ocorrido desde a primeira década do novo século (2001-2010), particularmente, da América do Sul - MERCOSUL e a particularidade do caminho brasileiro de busca de opções ao projeto liberal, desde os encaminhamentos dos governos Lula, abriu possibilidades de desenvolvimento de maior teor autóctone, contribuindo ainda mais com a complexidade da análise a ser desenvolvida na atualidade, nas primeiras décadas deste milênio.

\section{O RETROCESSO POLÍTICO E SOCIAL COMANDADO PELO REACIONARISMO PEQUENO-BURGUÊS: PRECONCEITOS, FUNDAMENTALISMO E FASCISMO SE UNEM PARA IMPEDIR O PROGRESSISMO DE ESQUERDA}

Essa alternativa, que vigorou ao largo de uma década (de modo geral e com fronteiras borradas, no período englobado pelos anos 2004-2014), encontrou, desde 2013, um refluxo conservador, financiado por setores da direita dos EUA e pelos reacionários internos em cada sociedade nacional sulamericana. Esse refluxo, articulando grupos financeiros, setores do capital industrial e comercial, mobilizado pela grande mídia corporativa empresarial dos vários países, cooptou com facilidade os setores sociais médios, cujo preconceito social, latente na cultura e ideologia pequeno-burguesa, foi alimentado com o medo da diluição social pela convivência com a emergente classe trabalhadora, decorrente da ampliação dos espaços sociais de vivência comum (shoppings, aeroportos, lojas, clubes, universidades, escolas etc.) (MANCEBO, 2017).

Por outro lado, os setores emergentes das classes populares (conhecidos no vocabulário oficial como classes "C" e "D"), embora não assumindo protagonismo político, se viram (foram projetados pelo discurso midiático) como a "nova classe média", perdendo a oportunidade de desenvolverem projetos sociais e políticos próprios e sendo "encaixados" no grande "sonho pequenoburguês do consumismo". De fato, uma parcela considerável dos antigos grupos sociais de pobres e 
famintos, classicamente excluídos da participação nos mecanismos de acesso ao consumo mínimo, à escolarização, à saúde, à moradia e à utilização dos serviços públicos e privados de amenização do esforço de reprodução social, efetivamente, ocupou um lugar de destaque na dinâmica reprodutiva do capital nesses países, principalmente no Brasil, por meio de seu recém-instalado poder de consumo (mesmo que de bens básicos) que se tornou o eixo deflagrador de taxas de crescimento econômico elevadas e de índices de desemprego em constante baixa, mesmo em meio à maior crise capitalista dos últimos setenta anos (KOPPER; DAMO, 2018).

Ainda é nebuloso o quadro que deparamos. A constituição de um novo Bloco Histórico é um processo que leva décadas, mesmo quando conscientemente perseguido com clareza e tenacidade. $\mathrm{O}$ panorama nacional (e regional sul-americano) não demonstra clareza, pelo menos não de forma hegemônica. Pelo contrário, o que se demonstra social e politicamente é a emergência de um 'momento histórico' de disputa, em que se engalfinham os velhos dirigentes das elites continentais e os novos personagens políticos e sociais ainda descoordenados e confusos, o que sugere a inexistência, até este momento, de uma clara opção e direcionamento hegemônico. No vazio de um projeto claro das próprias elites capitalistas, órfãs do discurso neoliberal, desgastado em todo o Continente, emerge um discurso de direita, neofascista cristã, eugenista, machista, homofóbico, reacionário em termos políticos, econômicos e sociais (ALMEIDA, 2019).

O debate plural e a divergência de projetos e de caminhos políticos e sociais acabam por, contraditoriamente, pesar contra o encaminhamento da mudança que pretende. Acrescente-se a este ponto da análise o necessário reconhecimento do papel desempenhado pela estrutura de manejo e difusão de informações, controlada pelos setores da elite do capital em nossas sociedades de classe. A mídia - falada, escrita, televisionada e, mais recentemente, controladora hegemônica das 'redes sociais virtuais' via internet - é efetivamente um elemento de construção de sentidos e interpretações conservadoras para o capital e reacionárias, em relação a qualquer projeto social, político e econômico alternativo. Efetivamente, a ação política de reação às mudanças, mesmo que mínimas, em conceitos e direcionamentos políticos e econômicos, tem tornado esse sistema informacional no maior 'partido político' das elites nacionais do Brasil, Venezuela, Argentina, Bolívia, Equador e Chile, para citar apenas alguns países envolvidos nesse contexto de mudanças sociais (ARRAIS NETO, 2020).

Com efeito, torna-se mais clara a motivação para o ataque às instituições escolares públicas de educação básica e à rede federal de ensino superior, representada pelas Universidades e Institutos Federais de Educação, Ciência e Tecnologia. De fato, nos transparece com luz cristalina o fato de que as instituições repositórias da perspectiva científica passaram a ser o foco da atuação nociva dos governos e grupos fundamentalistas e fascistas, e o quadro decorrente desse elemento demonstra a emergência de um momento crucial para a democracia e o progresso social no Brasil e na América Latina (ARRAIS NETO, 2020).

De fato, se observarmos o controle corporativo já tradicional exercido sobre o sistema da "grande mídia" (redes de televisão, rádio e jornais), associado ao controle difuso (porém efetivo) exercido sobre as novas "mídias digitais" ou "redes virtuais", veremos que o controle ideológico e sua utilização política pela "direita" é fato reconhecido", tendo tido influência na eleição de candidatos com perfil fascista ou reacionário em vários países. Os outros grandes "espaços institucionais" de formação ideológica são as igrejas e o sistema escolar, e o que se pode perceber numa análise que busque uma perspectiva abrangente é que se demonstra uma articulação de todos esses elementos.

As igrejas, forma institucionalizada de manifestação do fenômeno religioso na América Latina, são aqui basicamente constituídas pela Igreja Católica, ainda oficialmente majoritária entre a população, mas já não preponderante, e as igrejas autodenominadas evangélicas. Essas últimas, é necessário esclarecer, compõem um grupo heterogêneo que inclui desde as igrejas protestantes ou reformadas (luteranos, calvinistas, anglicanos) e seus desenvolvimentos provenientes dos EUA (batistas, metodistas, adventistas e outros) e igrejas mais recentes criadas no Brasil (Universal e várias outras) denominadas neopentecostais, baseadas na teologia da prosperidade e com uma forte relação com o sionismo (ALMEIDA, 2019).

${ }^{5} \mathrm{O}$ documentário "Privacidade Hackeada", os filmes "Snowden" e "O quinto poder" são apenas os elementos de denúncia pública que atestam um processo que ainda necessita de maior investigação. Educação em Revista|Belo Horizonte|v.37|e233354|2021 
As declarações dos grandes líderes das maiores dessas igrejas, referentes à eleição de Jair Bolsonaro, no Brasil, assim como em relação a todos os governos progressistas do Continente, teve apoteose no episódio do golpe de Estado ocorrido na Bolívia, no qual os ocupantes do palácio presidencial tomaram posse expondo uma Bíblia como garantia e justificação para rasgarem as definições constitucionais (DANIELLE, 2019).

O fundamentalismo se espraia, tanto entre as mais tradicionais igrejas reformadas, quanto no próprio catolicismo, presas da maré montante do pentecostalismo reacionário ao qual o fundamentalismo se associa e sobre o qual erige seus contrafortes e muralhas ideológicas. A situação da Igreja Católica é particularmente complexa, em decorrência da tradição de autoridade papal. Com um papa humanista e progressista, tanto religiosamente quanto social, econômica e politicamente, os grupos quantitativamente majoritários do pentecostalismo católico e os próprios segmentos aburguesados abrigados em alguns setores equilibram-se numa corda bamba da pretensa obediência, enquanto minam politicamente os efeitos objetivados por determinações, encíclicas, conselhos nacionais e conferências episcopais, de definido teor progressista. A posição social e política reacionária desses setores majoritários dos católicos estimulou o soerguimento de uma direita católica fascista, que emergiu do túmulo em que se imaginava sepultada pelo avanço da cultura técnica e científica, associada à popularização de políticas públicas laicizantes (DWa, 2018). Há que se acrescentar, em tais circunstâncias, o fato de que, mesmo as forças armadas se encontram articuladas com essa onda reacionária fundamentalista, deixando inclusive de cumprir seu papel constitucional de garantir a soberania do País, permitindo a entrega do patrimônio das nações, no caso brasileiro, o petróleo do Pré-Sal, empresas estratégicas como a Embraer, entre outros. No caso da Bolívia articulando o golpe de Estado, e, como no Brasil, Chile e Equador, agindo com extrema violência contra a população (SOUZA, 2019).

O quadro do que Althusser chamaria de Aparelhos Ideológicos de Estado (ALTHUSSER, 2009), então, demonstra uma propositura de disputa de poder. Controlando os aparelhos fundamentais (mídia física, mídia digital, famílias-igrejas), resta como gramsciana "trincheira" (GRAMSCI, 2011) na batalha pela hegemonia social e política o mundo da escolarização, mais susceptível aos conceitos e perspectivas da ciência, do laicismo, da história, da filosofia crítica, do pensamento livre. Torna-se óbvio para qualquer analista ou observador social o porquê do ataque desses grupos quando assumem o poder de Estado, no sentido de controlarem ideologicamente o sistema escolar de educação básica, e reprimirem, com cortes, ameaças e intervenções administrativas, o sistema público de ensino superior Universidades e Institutos Federais (no caso brasileiro) (GALINDO, 2019). O deslocamento da luta ideológica para as instituições de educação formal apenas reflete a importância desse espaço ou trincheira da sociedade civil como eixo decisivo da luta contra-hegemônica movida pelos setores sociais progressistas.

Por trás e subjacente à pulverização de objetos e aspectos particulares de luta (liberdade de gênero, antirracismo, feminismo, cidadania, autodeterminação dos povos originários, consciência de classe, movimento estudantil e protagonismo juvenil), a unidade da resistência anti-fundamentalismo é o eixo de um movimento que se contrapõe às determinações políticas e ideológicas emanadas dos grupos de direita religiosa que controlam politicamente os governos golpistas em toda a Sul-América.

\section{CONCLUSÃO: OS DESAFIOS ATUAIS PARA A EDUCAÇÃO E OS MOVIMENTOS SOCIAIS ORGANIZADOS}

Mais claramente, nos últimos três anos (2016-2019), vimos concretamente iniciar o desmonte acentuado dos direitos sociais e de políticas econômicas que privilegiavam o desenvolvimento autóctone latino-americano. A vitória da direita na Argentina - ainda que associada à sua derrocada - e a volta da esquerda, mas não sabemos como resultará, associada ao golpe jurídico-midiático-militar no Brasil, com a deposição da presidenta Dilma Rousseff, o assediamento ao governo da Venezuela, manifestado por meio de múltiplas tentativas de golpe, o golpe mais recente na Bolívia - e a também volta da esquerda que não sabemos o que resultará, o resultado eleitoral no Uruguai, com forte indício da utilização criminosa de estruturas difusas de informações falsificadas, de propaganda enganosa por meio da mídia digital e da mídia tradicional, igualmente como tem sido no Brasil, tiveram como resultado a destruição do consenso progressista e a instauração de uma maré cultural reacionária, preconceituosa contra o próprio povo, levando à regressão acentuada da estrutura de seguridade social. No Brasil, 
colecionamos, desde 2017, perda de direitos e mudanças com retrocesso na educação, cortes generalizados em áreas sociais, destruição de direitos do trabalho, tentativa de destruição da previdência pública atingida danosamente com perdas sociais consideráveis, cortes em investimentos científicos e acadêmicos, ataque direto às universidades, queimadas generalizadas pelo País, principalmente na Amazônia e Centro-Oeste, o total descaso do Governo federal em relação ao petróleo derramado na costa brasileira, entre outras políticas reacionárias relativas à conquista de direitos sociais e econômicos.

$\mathrm{O}$ quadro se exprime como grandemente similar no projeto antipopular em todo o Continente, levando a que tenhamos que começar a pensar mais profundamente, principalmente nós no Brasil, tradicionalmente de costas viradas para os países vizinhos e ajoelhados perante o poderio imperial do Norte. O momento em que conseguimos uma construção progressista de resistência decorreu da unidade de ação política de governos que optaram por superar divergências menores e erigir o possível a partir das convergências. O mesmo necessita, desde agora, ser articulado pelos movimentos sociais, e pelos educadores conscientes e mobilizados, no sentido de uma maior unidade de consciência política que favoreça a ação de resistência contra os desmontes. A transformação que sofremos todos os povos latino-americanos, neste final de segunda década, exige o desenvolvimento desses dois elementos - a consciência comum e a luta comum.

Esse quadro geral de transformações atinge a forma da sociedade capitalista, latinoamericana, e brasileira como modelo específico, em todos os seus aspectos, seja o produtivo e político, como vimos ressaltando, seja o cultural coletivo e os aspectos subjetivos das massas de trabalhadores, com influência determinante sobre a atual conjuntura da formação humana e dos processos específicos da qualificação dos trabalhadores. A busca de uma compreensão ampla, que dê conta da complexidade, das contradições e das transformações, tanto no nível global quanto em suas expressões continentais, regionais e locais, no caso do Brasil, das diversas regiões e de cada Estado, em particular, dialeticamente articulados como todo e como partes constitutivas, é a questão aberta da qual apenas iniciamos a exposição por via desta reflexão ensaística.

Apontamos para a necessidade de conjugar os esforços de uma compreensão empírica e da formulação teórica consequente que permita explicar e esclarecer concretamente o desenvolvimento atual da sociedade capitalista em sua totalidade e em seus aspectos específicos que cobrem a reestruturação produtiva, seu impacto e determinações sobre a qualificação e formação dos trabalhadores, a reestruturação do Estado brasileiro e suas políticas para a educação profissional e as transformações no perfil da subjetividade social e dos trabalhadores.

Esse esforço 'conjugado' não deve significar pensamento uniforme, mas parece demandar uma perspectiva "unitária" na pluralidade de possibilidades, de posições e de projetos. Em meio à diversidade de objetos de análise, de processos sociais avaliados, de encaminhamentos políticos e econômicos possíveis, é fundamental o estabelecimento de uma unidade de encaminhamento. Essa unidade, partindo da congregação de todos os grupos e setores progressistas contra o reacionarismo social, político e religioso, deve buscar um encaminhamento propositivo. Nisso também se encontra o grau maior da dificuldade: a tessitura de projetos e programas de ação unitários, em meio às necessidades cotidianas de resistência e, até mesmo, sobrevivência.

Neste texto, advogamos o papel, não apenas preponderante, mas também determinante central que tem-terá um processo educacional escolar crítico, abrangendo desde a educação básica à educação superior, calcado sobre valores humanistas plenos, desenvolvimento integral do ser humano, e formação política para uma cidadania universal. Somente essa construção humanizadora radical e plena pode nos manter congregados numa unidade de luta que se torne projeto de reconstrução. Unidade, diga-se claramente, de rumo, significando a superação da sociabilidade reificadora e desumanizante do capital e de sua civilização, afinal como expressaram Marx e Engels (2017), "tudo o que é sólido desmancha no ar".

\section{REFERÊNCIAS}

ALMEIDA, Ronaldo de. Bolsonaro Presidente: Conservadorismo, Evangelismo e a Crise Brasileira. Novos estud. CEBRAP, São Paulo, v. 38, n. 1, p. 185-213, Apr. 2019. Disponível em $<$ http://www.scielo.br/scielo.php?script=sci_arttext\&pid=S0101-

$33002019000100010 \& \operatorname{lng}=\mathrm{en} \& n r m=\mathrm{iso}>$. Acessado em 06/11/2019. 
ALTHUSSER, Louis. Aparelhos ideológicos de Estado. Graal, São Paulo, 2009.

ARRAIS NETO, Enéas. Desqualificação global do trabalho: a excentricidade de uma visão unitária da classe-que-vive-do-trabalho. In: Trabalho e Crítica, Anuário do GT Trabalho e Educação da ANPED, Florianópolis, 2002.

ARRAIS NETO, Enéas. Mundialização e Crise do Capital: a relação dialética entre essência e fenômeno na constituição do mundo do trabalho. In: Revista Educação em Debate. Ed. UFC, Fortaleza, v 1, n 45. P $86-95,2003$.

ARRAIS NETO, Enéas. Um mundo "sem fronteiras" ou capitalismo "sem controle" ? Regulação Social e a realidade dos novos papéis do estado nacional sob o capitalismo mundializado. In: ARRAIS NETO, Enéas et al (orgs) Trabalho, Capital mundial e formação dos Trabalhadores. Ed. UFC/Ed. SENAC. Fortaleza, p 127-142 2008.

ARRAIS NETO, Enéas. Empregabilidade, competências e Desqualificação dos Trabalhadores: a dança das palavras sobre o solo real das transformações produtivas. In: OLIVEIRA, Elenilce; SOUSA, Antonia (orgs) Educação profissional: análise contextualizada. Ed. UFC, Fortaleza, p 17-32, 2014.

ARRAIS NETO, Enéas. Reviravolta da nova economia Mundial: Transformações políticas, econômicas e educação na América do Sul. In: Conexões - Ciência e Tecnologia. Ed. IFCE, v. 14, n. 5, p 20-27, 2020.

BBC. As 6 armas 'invencíveis' apresentadas pelo presidente da Rússia, Vladimir Putin, em resposta aos EUA. Disponível em < https://www.bbc.com/portuguese/internacional-43258300> Acessado em 15/03/2018

BERTONHA, João Fábio. A Estratégia Nacional de Defesa do Brasil e a dos outros BRICs em perspectiva comparada. Rev. bras. polít. int., Brasília, v. 56, n. 2, p. 112-130, Dec. 2013. Disponível em <http://www.scielo.br/scielo.php?script=sci_arttext\&pid =S003473292013000200007\&lng=en\&nrm=iso $>$. Acessado em 26/11/2019.

BRAZ, Marcelo. O golpe nas ilusões democráticas e a ascensão do conservadorismo reacionário. Serv. Soc. Soc., São Paulo, n. 128, p. 85-103, Apr. 2017. Disponível em $<$ http://www.scielo.br/scielo.php?script=sci_arttext\&pid=S0101-66282017000100085\&lng= en\&nrm=iso >. Acessado em 26/11/2019.

CHESNAIS, François. A Mundialização do Capital. São Paulo: Xamã, 1996.

CHESNAIS, François et al. Uma nova Fase do Capitalismo? São Paulo: Xamã, 2003.

DANIELLE, Beatriz. Pastor denuncia a participação das igrejas evangélicas brasileiras no golpe na Bolívia. Disponível em $<\mathrm{https}$ ://www.diariodocentrodomundo.com.br/pastor-denuncia-aparticipacao-das-igrejas-evangelicas-brasileiras-no-golpe-na-bolivia/ > Acessado em 27/11/2019.

DOWBOR, Ladislau. A era do capital improdutivo. São Paulo: Outras Palavras \& Eutonomia Literária, 2018.

DWa. Opinião: Igrejas neopentecostais ameaçam democracia na América Latina. Disponível em < https://www.dw.com/pt-br/opinião-igrejas-neopentecostais-ameaçam-democracia-na-américalatina/a-42511616 > Acessado em 16/04/2018.

DWb. Após o bombardeio, a guerra de palavras. Disponível em < https://www.dw.com/pt-br/apóso-bombardeio-a-guerra-de-palavras/a-43385937 > Acessado em 16/04/2018.

ESCOBAR, Pepe. Guerra Híbrida: a nova guerra do século 21 no Brasil. Disponível em < https://dialogosdosul.operamundi.uol.com.br /brasil/52223/guerra-hibrida-a-nova-guerra-do-seculo21-no-brasil > Acessado em 26/11/2019. 
GALINDO, Rogério. Os sete pecados de Bolsonaro contra as universidades federais. Disponível em < https://www.plural.jor.br/colunas/caixa-zero/os-sete-pecados-de-bolsonaro-contra-asuniversidades-federais/ > Acessado em 27/11/2019.

GRAMSCI, Antonio. Cadernos do Cárcere. V 2, Ed. Civilização Brasileira, São Paulo, 2011.

KOPPER, Moisés; DAMO, Arlei. A emergência e evanescência da nova classe média brasileira. Horiz. antropol., Porto Alegre, ano 24, n. 50, p. 335-376, jan./abr. 2018.

MANCEBO, Deise. Crise Político-Econômica no Brasil: Breve Análise da Educação Superior. Educ. Soc., Campinas, v. 38, n. 141, p. 875-892, Dec. 2017. Disponível em <http://www.scielo.br/scielo.php?script=sci_arttext\&pid=S0101-73302017000400875\&lng= en\&nrm=iso $>$. Acessado em 26/11/2019.

MARX, Karl. O Capital - Crítica da Economia Política. Volume III, Tomo 1 (Coleção Os Economistas), Abril S/A Cultural, São Paulo 1984.

MARX, Karl; ENGELS, Friedrich. Manifesto Comunista. Boitempo, São Paulo, 2017.

SANTOS, Theotonio dos. Economia Mundial, Integracion regional y Desarrollo sustentable: Las nuevas tendências y la integracion latino-americana. Derrama Magistral, Peru, 2010.

SANTOS, Theotonio dos. Imperialismo y Dependencia. Caracas: Fundación Biblioteca Ayacucho, 2011.

SOUSA, Antonia A.; ARRAIS NETO, Enéas et al. Trabalho, Capital Mundial e Formação dos Trabalhadores. Fortaleza: Ed. UFC/Ed. SENAC, 2008.

SOUZA, Marlon. Forças Armadas, subordinação aos EUA, democracia e realismo periférico. Disponível em < https://www.pagina13.org.br/forcas-armadas-subordinacao-aos-eua-democracia-erealismo-periferico/ > Acessado em 10/12/2019.

Submetido: $24 / 01 / 2020$

Aprovado: 11/02/2021 